\title{
Assessing the ability of the Sacral Autonomic Standards to document bladder and bowel function based upon the Asia Impairment Scale
}

\author{
Marca Alexander $^{1} \cdot$ Conley Carr ${ }^{1} \cdot$ Jagger Alexander $^{2} \cdot$ Yuying Chen $^{1} \cdot$ Amie McLain $^{1}$
}

Received: 23 August 2019 / Revised: 14 September 2019 / Accepted: 17 September 2019

(c) The Author(s), under exclusive licence to International Spinal Cord Society 2019

\begin{abstract}
Study design Retrospective review of data.

Objective To determine if there is a relationship between the Asia Impairment Scale (AIS) and the bladder and bowel components of the International Standards to Document Remaining Autonomic Function after SCI (ISAFSCI).

Setting University-Based Academic Rehabilitation Program.

Methods Retrospective cross-sectional study assessing International Standards for Neurologic Classification After SCI (ISNCSCI) examination along with bladder and bowel components of the ISAFSCI.

Results Subjects with AIS A injuries were statistically less likely to have history of bladder control and bowel control per investigator determination and bladder sensation via self-report versus patients categorized with AIS B injuries. Self-reported history of bowel sensation and control of voiding were more likely in subjects with C, D, or E injuries than with B injuries. Bowel and bladder control as determined by investigator and bladder and bowel sensation and control as self-reported were all statistically less likely in persons with AIS A injuries versus CDE.

Conclusions This retrospective study provides initial data regarding components of the bladder and bowel sections of the sacral ISAFSCI and AIS. Further prospective research is needed to further characterize the relationship between retention of bladder and bowel sensation and function and the AIS. We suggest that incorporation of the sacral components of the ISAFSCI into the ISNCSCI may be beneficial to obtain further information about retention of sacral function with specific patterns of injury.
\end{abstract}

\section{Introduction}

Spinal cord injury (SCI) causes a significant impact on the affected individual. In addition to a loss of motor function and sensation, the injury causes profound disruption of the person's control of bodily functions. Loss of bladder and bowel control are two of the most significant problems for persons with SCIs [1]. These deficits result in significant personal distress related to intimacy issues, strained partner relationships, and role changes for family members and

Marca Alexander

spinalcordmd@live.com

1 Department of Physical Medicine and Rehabilitation, University of Alabama at Birmingham School of Medicine, Birmingham, AL, USA

2 Vanderbilt University, Nashville, TN, USA friends [2]. Moreover, the lack of the ability to naturally control voiding and defecation results in the need for costly appliances and medications to maintain continence.

As compared to studies pertaining to ambulation, few reports have addressed the recovery of bladder [3-5] and bowel function, based upon injury pattern. With regard to the lower urinary tract, continence and bladder emptying 1 year after SCI were predicted by the sensation in S3 for light touch, Spinal Cord Indepence Measure subscales for sphincter management and respiration, and lower extremity motor score [4]. Additionally, persons with greater perianal pinprick, which correlates with S4-5 sensation, had greater ability to void volitionally [4]. We were unable to find any studies predicting recovery of bowel control.

In contrast, many reports have addressed recovery of ambulation after SCI $[6,7]$. The majority have utilized the International Standards for the Neurologic Classification of SCI (ISNCSCI) as the standard to document remaining neurologic function after SCI. Moreover, studies have 
shown that the amount of remaining supraspinal control of motoric function is the best predictor for regaining ambulation [6]. One aspect of neurologic function that has been studied to see if it is predictive of recovery of motor function is that of the lower sacral spinal cord: voluntary anal sphincter control, deep anal sensation and sensation at S4-5. These are the components of the ISNCSCI that comprise sacral sparing; and retention of sensation defines an AIS B injury, whereas, concomitant retention of voluntary anal contraction would signify an AIS C injury. Despite use in clinical trials [8], retrospective and prospective research has documented retention of deep anal sensation is not predictive of motor function [9].

In 2009, a system of classification for remaining autonomic function after SCI, the International Standards for Autonomic Function after SCI (ISAFSCI) was developed through consensus of an international team of experts [10]. The standards were simplified in 2012 [11] and have been assessed for clinical adherence [12], utility of educational workshops [13], and inter-rater reliability [14]. These standards include sections where the clinician can describe the impact of specific injuries on respiratory, cardiovascular, sudomotor, thermoregulatory, bladder, bowel, and sexual functions. Most recently the sacral components of the autonomic standards (assessing bladder, bowel and sexual function) have been utilized in a clinical trial [15]; however, to date we were unable to find any attempts to determine a relationship between these components and the AIS.

This retrospective cross-sectional pilot study was performed to determine whether persons with AIS B injuries would show differential bladder or bowel function as compared to persons with absent sacral sensation (AIS A) or greater retention of sacral responses (AIS C-E).

\section{Methods}

The urodynamic and examination methods have been previously described in a prospective study assessing specific patterns of sensory retention and bladder control [3]. Institutional review board approval was obtained for the study. As part of this study, participants underwent an ISNCSCI examination along with queries of their bladder and bowel function based upon the ISAFSCI [10]. Subsequently, participants underwent urodynamic testing to determine whether there was sensation of bladder filling and results were previously described and published.

In this study, a retrospective review of the data regarding the participant's AIS and their control of bladder and bowel function based upon investigator recorded determination and self-reported data was performed. We hypothesized that there would be a greater retention of sensation and control in participants with more neurologic function as determined by the AIS. Moreover, we believed that both the investigator-determined and self-reported data would show statistically significant differences.

\section{Subjects}

Out of an original 79 participants, there were 72 individuals with SCIs who had adequate data to participate in this secondary analysis. Levels of injury ranged from C2 to L4. Participants were a mean of $35 \pm 13.0$ years of age. There were 41 males and 31 females. Mean years of education was $13.1 \pm 2.5$. There were 38 participants with AIS A injury, 5 with AIS B and 29 with C-E injuries. All participants had a rectal examination performed and documentation of anal sensation and voluntary contraction were used to document the neurologic status, e.g., those participants with AIS A injury had no sensation and no contraction, whereas AIS B only had sensation and other groups had sensation plus voluntary contraction.

\section{Statistics}

SPSS version 23 was used to analyze results. Cross tabs of investigator-determined bladder and bowel function are in Table 1, while self-reported bladder function is in Table 2, and self-reported bowel function is in Table 3. Statistical analysis of various AIS impairment scores versus degree of function is shown in Table 4. Between group comparisons were performed based upon AIS A versus B versus CDE for bowel and bladder control and sensation as determined by the physician and based upon self-report. Pair-by-pair Jonckheere-Herpstra Test was performed to analyze between group differences based upon investigator's determination of participants bladder and bowel control and participants self-report of historical control of these functions. The Jonckheere-Herpstra test was chosen because it is a non-parametric test which best allows for statistical analysis comparing the two ordered categorical variables: the AIS and the categorized degree to which the patients had bladder and bowel sensation or control (i.e., present, partially present, absent).

\section{Results}

Statistically significant differences were found in history of bladder control and bowel control per investigator and bladder sensation via self-report between participants categorized as an "A" on the AIS versus participants categorized as a "B" on the AIS. As would be expected by the classification, sample groups of participants categorized as "B" had a tendency towards greater bladder control; 
Table 1 Crosstabulation of Bladder and Bowel Control Data as deemed by investigator based upon AIS

\begin{tabular}{|c|c|c|c|c|c|c|c|}
\hline \multirow[t]{2}{*}{ AIS scale } & \multirow[t]{2}{*}{$N$} & \multicolumn{3}{|c|}{$\begin{array}{l}\text { Bowel control } \\
n=72\end{array}$} & \multicolumn{3}{|c|}{$\begin{array}{l}\text { Bladder control } \\
n=72\end{array}$} \\
\hline & & Present & Partially present & Absent & Present & Partially present & Absent \\
\hline A & 38 & 1 & 7 & 30 & 0 & 10 & 28 \\
\hline B & 5 & 0 & 5 & 0 & 0 & 4 & 1 \\
\hline $\mathrm{C}, \mathrm{D}, \mathrm{E}$ & 29 & 16 & 9 & 4 & 11 & 11 & 7 \\
\hline Total & 72 & 17 & 21 & 34 & 11 & 25 & 36 \\
\hline
\end{tabular}

Table 2 Self-reported history of bladder sensation and voiding control in persons with SCI based upon AIS

\begin{tabular}{|c|c|c|c|c|c|c|c|}
\hline \multirow[t]{2}{*}{ AIS } & \multirow[t]{2}{*}{$N$} & \multicolumn{3}{|c|}{$\begin{array}{l}\text { History of bladder sensation } \\
n=71\end{array}$} & \multicolumn{3}{|c|}{$\begin{array}{l}\text { History of voiding control } \\
n=70^{\mathrm{a}}\end{array}$} \\
\hline & & Present & Partially present & Absent & Present & Partially present & Absent \\
\hline A & 38 & 4 & 17 & 17 & 1 & 6 & 30 \\
\hline B & 4 & 1 & 3 & 0 & 0 & 2 & 2 \\
\hline$C, D, E$ & 29 & 15 & 11 & 3 & 9 & 16 & 4 \\
\hline Total & 71 & 20 & 31 & 20 & 10 & 24 & 36 \\
\hline
\end{tabular}

${ }^{\mathrm{a}}$ Data was not able to be obtained on one AIS A participant regarding history of voiding control however, no statistically significant differences were obtained for the differences between "A" and "B" participant groups for the other variables surveyed: history of voiding control, history of bowel sensation, and history of bowel control. Proportionally, "B" participants did have fewer cases of "absent" responses for all three variables than "A" participants, but there were not enough individuals measured to have any significant results.

Similarly, in comparing AIS "B" groups with combined AIS "C", "D", and "E" groups, some variables showed significant differences while others did not. Self-reported bowel sensation and voiding control were more likely in subjects with $\mathrm{C}, \mathrm{D}$, or $\mathrm{E}$ injuries than with $\mathrm{B}$ injuries. Moreover, there was a strong trend in investigatordetermined bowel control in participants with B versus $C$, $\mathrm{D}$, and $\mathrm{E}$ injuries $(p=0.05)$. No significant differences were found between the groups for the other variables surveyed.

All variables had measured significant differences between AIS "A" and combined AIS "C", "D", and "E" with $p<0.02$. As expected, the "C", "D", and "E" groups had much greater proportions of combined present and partially present conditions in each of the measured variables than the "A" groups.

\section{Discussion}

Our data are important because they provide an initial overview of how the sacral components of bladder and bowel function of the ISAFSCI are related to the AIS. As expected, there was greater awareness of the sensation of the need to void, have a bowel movement and a greater history of voiding control in persons with AIS B lesions versus AIS A. This is expected because of the incompleteness of sacral function in the B group versus the A group. Similarly, history of voiding control and bowel sensation were more likely in subjects with $\mathrm{C}, \mathrm{D}$, or $\mathrm{E}$ than with $\mathrm{B}$ injuries. Finally, AIS A participants were statistically less likely to have control over all the functions than participants with C-E injuries.

Despite these findings, not all variables were statistically significant between groups. We attribute this to weaknesses of our study, which are the small number of participants and the retrospective nature of this analysis. We believe that further expansion of this study such as can be achieved in a large prospective study monitoring the bladder and bowel recovery patterns of participants with specific AIS groups based upon the ISAFSCI would provide statistically significant results amongst each category of AIS scale.

Clinical trials have targeted recovery of recovery of function using the AIS; however, the meaning of the conversion from AIS A status to AIS B status has not been fully assessed. One study showed there were statistically greater hospitalization costs when comparing thoracic SCI participants across AIS grades [16]. Another showed that people with AIS A injuries and complete lower motor neuron injuries are less likely to have orgasms as compared to participants with all other levels and degrees of injuries [17]. Previous data showed that AIS B participants were more likely to be more independent in bladder management [18], and it was hypothesized that increased bladder sensation could be the reason. On the other hand, sparse research has assessed these responses and a recent study by the same group looking at AIS A versus B conversions 
Table 3 Self-reported sensation and control of bowel movements based upon AIS

\begin{tabular}{|c|c|c|c|c|c|c|c|}
\hline \multirow[t]{2}{*}{ AIS } & \multirow[t]{2}{*}{$N$} & \multicolumn{3}{|c|}{$\begin{array}{l}\text { History of bowel sensation } \\
n=54\end{array}$} & \multicolumn{3}{|c|}{$\begin{array}{l}\text { History of bowel control } \\
n=52\end{array}$} \\
\hline & & Present & Partially present & Absent & Present & Partially present & Absent \\
\hline A & 28 & 2 & 7 & 19 & 3 & 7 & 17 \\
\hline B & 3 & 0 & 1 & 2 & 0 & 2 & 0 \\
\hline C, D, E & 23 & 12 & 9 & 2 & 15 & 4 & 4 \\
\hline Total $N$ & 54 & 14 & 17 & 23 & 18 & 13 & 21 \\
\hline
\end{tabular}

Table 4 Investigator determined and self-reported sensation and control of bladder and bowel

\begin{tabular}{|c|c|c|c|c|c|c|c|c|c|}
\hline & \multicolumn{3}{|c|}{ AIS A versus B } & \multicolumn{3}{|c|}{ AIS A versus $C, D, E$} & \multicolumn{3}{|c|}{ ASIA B versus $C, D, E$} \\
\hline & $\begin{array}{l}\text { Test } \\
\text { statistic }\end{array}$ & $\begin{array}{l}\text { Standard test } \\
\text { statistic }\end{array}$ & $p$-value & $\begin{array}{l}\text { Test } \\
\text { statistic }\end{array}$ & $\begin{array}{l}\text { Standard test } \\
\text { statistic }\end{array}$ & $p$-value & $\begin{array}{l}\text { Test } \\
\text { statistic }\end{array}$ & $\begin{array}{l}\text { Standard test } \\
\text { statistic }\end{array}$ & $p$-value \\
\hline Bladder Control PI ${ }^{\mathrm{a}}$ & 44.000 & -2.380 & 0.009 & 223.000 & -4.577 & $<0.001$ & 53.5000 & -0.992 & $<0.161$ \\
\hline Bowel control PI & 22.500 & -3.436 & $<0.001$ & 140.500 & -5.669 & $<0.001$ & 42.500 & -1.606 & 0.054 \\
\hline $\begin{array}{l}\text { Bladder sensation } \\
\mathrm{SR}^{\mathrm{b}}\end{array}$ & 39.500 & -1.722 & 0.042 & 256.000 & -3.948 & $<0.001$ & 47.000 & -0.674 & 0.250 \\
\hline Voiding control SR & 52.000 & -1.344 & 0.090 & 156.500 & -5.412 & $<0.001$ & 28.000 & -1.836 & 0.033 \\
\hline Bowel sensation SR & 42.500 & 0.041 & 0.484 & 98.500 & -4.513 & $<0.001$ & 8.500 & -2.274 & 0.011 \\
\hline Bowel control SR & 13.000 & -1.375 & 0.850 & 122.500 & -3.926 & $<0.001$ & 12.000 & -1.258 & 0.104 \\
\hline
\end{tabular}

Statistic $=$ Pair-by-pair Jonckheere-Herpstra Test

${ }^{\text {a}}$ Per investigator

${ }^{\mathrm{b}} \mathrm{Self}$ report

focused on the lack of improvement in ambulatory capacity in association with conversion to AIS B rather than sacral function after injury [19].

More attention needs to be paid to the recovery of sacral autonomic function in clinical trials pertaining to neurologic recovery after SCI. However, review of relevant outcome measures [20-22] reveals a lack of information regarding retention of bladder sensation and control of voiding in commonly used outcome measures that focus on quality of life issues.

The autonomic standards are currently in a process of revision [23]. One goal of the autonomic standards is to communicate the degree of remaining sacral autonomic function. Thus, they provide a foundation for the study of recovery of sacral autonomic responses through consistent documentation of the degree of remaining bladder and bowel control and sensation and the degree of preservation of specific sexual responses. To our knowledge, the sacral component of the ISAFSCI represents the only available measure where all three functions are grouped. Our study provides a first comparison of the AIS with specific components of sacral autonomic responses assessed via the standards. Our results are retrospective and preliminary with the number of subjects insufficient to obtain statistical significance in all areas assessed. However, these findings should be considered in association with a previous report that documented strong agreement in lower urinary tract, bowel and sexual function with kappa values from 0.41-0.6 [14]. Based upon these data, we believe that further assessment and development of the sacral autonomic components of the ISAFSCI is warranted. We believe that the sacral components of the ISAFSCI should be added to the ISNCSCI. Additionally, we believe that further development of the sacral components of the autonomic standards may be appropriate as an outcome measure specifically tailored to predict recovery of sacral function after SCI.

\section{Conclusion}

Regardless of which next steps are taken, bladder, bowel, and sexual function are important aspects of quality of life for persons with SCI, and more attention needs to be paid to determining the anticipated impact of degrees of AIS impairment on the preservation of these functions. Although we have substantial information regarding the impact of specific degrees of SCI on sexual responses such as orgasm and arousal [17, 24, 25], it is important to have greater knowledge of the natural history of specific injury patterns on bladder and bowel function. With this information, researchers will have better data to develop and document therapies to improve bladder and bowel function after SCI. 
Acknowledgements This work was supported by the United States National Institute of Disability, Independent Living, and Rehabilitation Research.

\section{Compliance with ethical standards}

Conflict of interest The authors declare that they have no conflict of interest.

Publisher's note Springer Nature remains neutral with regard to jurisdictional claims in published maps and institutional affiliations.

\section{References}

1. Estores IM. The consumer's perspective and the professional literature: what do persons with spinal cord injury want? J Rehabilitation Res Dev. 2003;40:93-8.

2. Braaf S, Lennox A, Nunn A, Gabbe B. Social activity and relationship changes experienced by people with bowel and bladder dysfunction following spinal cord injury. Spinal Cord. 2017;55: 679-86.

3. Alexander MS, Carr C, Chen Y, McLain A. The use of the neurologic exam to predict awareness and control of lower urinary tract function post SCI. Spinal Cord. 2017;55:840-3.

4. Pavese C, Schneider MP, Schubert M, Curt A, Sciovoletto G, Finazzi-Agro E, et al. Prediction of bladder outcomes after traumatic spinal cord injury: a longitudinal cohort study. PLoS Med. 2016;13:e1002041.

5. Weiss DJ, Fried GW, Chancellor MB, Herbison GH, Ditunno JF, Staas WE. Spinal cord injury and bladder recovery. Arch Phys Med Rehabil. 1996;77:1133-5.

6. Field-Fote EC, Yang JF, Basso DM, Gorassini MA. Supraspinal control predicts locomotor function and forecasts responsiveness to training after spinal cord injury. J Neurotrauma. 2017;34: $1813-25$.

7. Comingo A, Abdulaziz A, Asiri Y, Eng J. Lam T \& SCIRE. A systematic review on the effects of pharmacological agents on walking function in people with spinal cord injury. J Neurotrauma. 2012;29:865-79.

8. Lammertse DP, Jones LA, Charlifue SB, Kirshblum SC, Apple $\mathrm{DF}$, Ragnarsson KT, et al. Autologous incubated macrophage therapy in acute, complete spinal cord injury: results of the phase 2 randomized controlled multicenter trial. Spinal Cord. 2012;50: 661-71.

9. Marino RM, Schmidt-Read M, Kirshblum S, Dyson-Hudson TA, Tansey K, Morse LR, et al. Reliability and validity of S3 pressure sensation as an alternative to deep anal pressure in neurologic classification of persons with spinal cord injury. Arch Phys Med Rehabil. 2016;97:1642-6.

10. Alexander MS, Biering-Sorensen F, Bodner D, Brackett NL, Cardenas D, Charlifue $\mathrm{S}$, et al. International standards to document remaining autonomic function after spinal cord injury. Spinal Cord. 2009;47:36-43.

11. Krassioukov A, Biering-Sorensen F, Donovan W, Kennelly M, Kirshblum S, Krogh K, et al. International standards to document remaining autonomic function after spinal cord injury (ISAFSCI). Top Sci Rehabil. 2012;18:283-96.

12. Squair J, le Nobel G, Noonan V, Raina G, Krassioukov A. Assessment of clinical adherence to the international autonomic standards following spinal cord injury. Spinal Cord. 2015;53: 668-72.

13. Round AM, Park SE, Walden K, Noonan VK, Towns AF, Krassioukov A. An evaluation of the international standards to document remaining autonomic function after Spinal Cord Injury: input from the international community. Spinal Cord. 2017;55: 198-203.

14. Davidson RA, Carlson M, Fallah N, Noonan VK, Elliott SL, Joseph $\mathrm{J}$, et al. Inter-rater reliability of the international standards to document remaining autonomic function after spinal cord injury. J Neurotrauma. 2017;34:552-8.

15. Morrison S, Lorenz D, Eskay C, Forrest G, Basso M. Longitudinal recovery and reduced costs after 120 sessions of locomotor training for motor incomplete spinal cord injury. Arch Phys Med Rehabil. 2017; https://doi.org/10.1016/j.apmr.2017.10.003.

16. Dukes EM, Kirshblum S, Aimetti A, Qin S, Bornheimer R, Oster G. Neurosurgery. 2017; https://doi.org/10.1093/neuros/nyx425 (epub ahead of print).

17. Alexander M, Marson L. Orgasm and SCI: What do we know? Spinal Cord. 2018;56:538-47.

18. Kirshblum S, Botticello Am, Lammertse DP, Marino RJ, Chiodo $\mathrm{AE}$, Jha $\mathrm{A}$. The impact of sacral sensory sparing in motor complete spinal cord injury. Arch Phys Med Rehabil. 2011;92:376-83.

19. Kirshblum SC, Botticello AL, Dyson-Hudson TA, Byrne R, Marino RJ, Lammertse D. Patterns of sacral sparing components on neurologic recovery in newly injured persons with traumatic spinal cord injury. Arch Phys Med Rehabil. 2016;97:1647-55.

20. Costa P, Perrouin-Verbe B, Colvez A, Didier J, Marquis P, Marrel $\mathrm{A}$, et al. Quality of life in spinal cord injury patients with urinary difficulties. Development and validation of qualiveen. Eur Urol. 2001;39:107-13.

21. Patel DP, Elliott SP, Stoffel JT, Brant WO, Hotaling JM, Myers JB. Neurourol Urodyn. 2016;35:8-14.

22. Erdem D, Hava D, Keskinoglu P, Bircan C, Peker O, Krogh K, et al. Reliability, validity and sensitivity to change of neurogenic bowel dysfunction score in patients with spinal cord injury. Spinal Cord. 2017; https://doi.org/10.1038/sc.2017.82 (epub ahead of print).

23. Alexander M, Wecht J, Krassioukov A. International Autonomic Standards Committee. Spinal Cord Ser Cases. 2017;3:17100. https://doi.org/10.1038/s41394-017-0025-8.

24. Sipski ML, Alexander CJ, Gomez O, Spalding J. The effects of spinal cord injury on 252 psychogenic sexual arousal in males. J Urol. 2007;177:247-51.

25. Sipski ML, Alexander CJ, Rosen RC. Sexual arousal and orgasm in women: effects of spinal cord injury. Ann Neurol. 2001;49:35-44. 